\section{TÀI LIÊU THAM KHẢO}

1. De, A.K., et al (2013). A Case of Congenital Erythropoietic Porphyria without Hemolysis. Indian J Dermatol, 58(5): p. 407.

2. Desnick RJ, Astrin KH (2002). Congenital erythropoietic porphyria: advances in pathogenesis and treatment. $\mathrm{Br}$ ] Haematol, 117:779-795.

3. Katugampola RP, Anstey AV, Finlay AY, Whatley S, Woolf J, Mason N, Deybach JC, Puy H, Ged C, de Verneuil H, Hanneken S, Minder $E$, Schneider-Yin $X$, Badminton MN (2012). A management algorithm for congenital erythropoietic porphyria derived from a study of 29 cases. Br J Dermatol, 167:888-900.

4. Maniangatt, S.C. et al (2004). A rare case of porphyria. Ann Acad Med Singapore,33(3): p. 359-61.

5. Mathews MA, Schubert HL, Whitby FG, Alexander KJ, Schadick K, Bergonia HA, Phillips JD, Hill CP (2001). Crystal structure of human uroporphyrinogen III synthase. EMBO J, 20:5832-5839.

6. Mazurier F, Géronimi F, Lamrissi-Garcia I, Morel C, Richard E, Ged C, Fontanellas A, MoreauGaudry F, Morey M, de Verneuil H (2001). Correction of deficient CD34+ cells from peripheral blood after mobilization in a patient with congenital erythropoietic porphyria. Mol Ther, 3:411-417.

7. Moghbeli M, Maleknejad M, Arabi A, Abbaszadegan MR (2012). Mutational analysis of uroporphyrinogen III cosynthase gene in Iranian families with congenital erythropoietic porphyria. Mol Biol Rep, 39:6731-6735.

8. Ohgari $Y$, Sawamoto M, Yamamoto M, Kohno H, Taketani S (2005). Ferrochelatase consisting of wild-type and mutated subunits from patients with a dominant-inherited disease, erythropoietic protoporphyria, is an active but unstable dimer. Hum Mol Genet, 14:327-334.

9. Takamura $\mathbf{N}$, Hombrados $I$, Tanigawa $K$, Namba $H$, Nagayama $Y$, de Verneuil $H$, Yamashita S (1997). Novel point mutation in the uroporphyrinogen III synthase gene causes congenital erythropoietic porphyria of a Japanese family. Am J Med Genet, 70:299-302.

10. Wiederholt $T$, Poblete-Gutiérrez $P$, Gardlo K, Goerz G, Bolsen K, Merk HF, Frank J (2006). Identification of mutations in the uroporphyrinogen III cosynthase gene in German patients with congenital erythropoietic porphyria. Physiol Res, 55(suppl 2): S85-S92.

\title{
BƯớC ĐẦU ĐÁNH GIÁ HIỆU QUẢ ĐIỀU TRI CỦA DECITABINE TRÊN NGƯỜI BÊNH LOAN SINH TỦY TẠI BỆNH VIỆN TRUYỀN MÁU HUYẾT HỌC
}

\section{TÓM TẮT}

Muc tiêu: Đánh giá hiệu quả điêu tri và độc tính của việc điêuu trị Decitabine trên người bệnh loạn sinh tủy (MDS). Đối tượng và phương pháp nghiên cứu: Mô tả hàng loạt ca, các người bệnh được chẩn đoán MDS, thỏa tiêu chuẩn nhân vào và được điều tri với Decitabine $20 \mathrm{mg} / \mathrm{m}^{2} /$ ngày x 5 ngày, từ tháng 01/2019 đến tháng 7/2021 tại bệnh viện Truyền máu Huyết học (BV.TMHH). Đánh giá đáp ứng điều trị theo IWG 2006. Kết quả: 32 người bệnh (18 nam, 14 nữ) được phân loại theo WHO 2016, chiếm tỉ lệ cao nhất là nhóm MDS tăng tế bào non-2 (MDS-EB2) $(56,2 \%)$ và nhóm nguy cơ rất cao theo IPSS-R (56,2\%). Người bênh được điêuu trị từ 1 đến 11 chu kỳ Decitabine với tỉ lệ đáp ứng toàn bộ (ORR: CR+PR) là 21,9\%; trong đó đạt đáp ứng hoàn toàn $(\mathrm{CR})$ là $12,5 \%$ và đạt đáp ứng một phân (PR) là 9,4\%. Đáp ứng tủy xương hoàn toàn (mCR) là $25 \%$. Nhóm ngưới bệnh điêu trị >4 chu kỳ

*Đại hoc Y Dước Tp. Hồ Chí Minh

**Bêenh viên Truyền máu - Huyết hoc.

Chịu trách nhiệm chính: Lê Thị Hà

Email: halethi1010@gmail.com

Ngày nhận bài: 4.6.2021

Ngày phản biên khoa hoc: 2.8.2021

Ngày duyệt bài: 10.8 .2021
Lê Thị Hà*, Trịnh Lê Quốc Vũ**, Huỳnh Thiện Ngôn**, Nguyễn Phương Liên**

có tỉ lê đạt $O R R, C R$; thời gian sống còn toàn bộ(OS); sống khồng tiến triển bệnh (PFS); sống không tiển triển thành $A M L(A M L F S)$ cao hơn nhóm điêu trị $\leq 4$ chu kỳ ( $p$ lần lượt: 0,$032 ; 0,009 ; 0,007 ; 0,01 ; 0,009$ ). Tỉ lệ người bệnh độc lập truyền hồng cẩu, tiếu cầu tăng theo chu kỳ, tại chu kỳ 6 cùng bằng $40 \%$. Thời gian theo dõi trung vi là 7 tháng với trung vị của OS; PFS; AMLFS lần lượt là: 12,3; 7,9; 11,6 (với độ tin cậy $95 \%)$. Nhóm người bệnh đạt $\mathrm{PR} / \mathrm{CR}$ có $\mathrm{OS}$ và̀ AMLFS kéo dài hơn nhóm không đạt ( $p$ lần lượt: 0,004 ; 0,016). Biến chứng độ III-IV thường gặp trong quá trình điều trị là: nhiếm trùng $68,7 \%$; giảm bạch cầu hat $68,7 \%$; giảm tiểu cầu $65,6 \%$; thiêu máu $56,2 \%$;. Tử vong do biến chứng điều trị là $18,7 \%$ (chủ yếu do biễn chứng nhiễm trùng kết hợp giảm bạch câuu hạt năng). Kết luân: Sử dụng Decitabine trong điều tri MỉS cho thây hiệu quả trong giảm nhu cầu truyền chể phẩm máu, giúp cải thiện huyết học, đồng thời giúp kéo dài thời gian OS, PFŚ, AMLFS cho người bệnh, đặc biêt ở nhóm người bênh có đáp ứng điêu trị.

Tư khóa: Loạn sinh tủy, decitabine

\section{SUMMARY \\ PRELIMINARY ASSESSMENT OF DECITABINE EFFECTIVENESS IN TREATMENT OF MYELODYSPLASTIC SYNDROMES AT BLOOD TRANSFUSION HEMATOLOGY HOSPITAL}


Aims: To evaluate the therapeutic efficacy and toxicity of decitabine in MDS (Myelodysplastic syndromes) patients. Subjects and methods: Descriptive case series. Patients who were diagnosed with MDS, suitable with the inclusion criteria and received treatment with decitabine $20 \mathrm{mg} / \mathrm{m}^{2} /$ day $\times 5$ days from January 2019 to July 2021 were included and analyzed retrospectively. Treatment response evaluation is set according to IWG 2006. Results: Thirty-two patients were selected (18 males, 14 females) in whom the highest proportion was MDSEB2 (56.2\%) according to WHO 2016 classification. The vast majority according to IPSS-R was the very high-risk group with $56.2 \%$. Patients were treated from 1 to 11 cycles of decitabine with an overall response rate (ORR) of 21.9\%; of which complete response (CR) $12.5 \%$ and partial response (PR) $9.4 \%$. Complete bone marrow response (mCR) was 25\%. The group of patients treated for $>4$ cycles achieved a higher ORR, CR, time overall survival (OS), progression-free survival (PFS), acute myeloid leukemia-free survival (AMLFS) more than those treated with $\leq 4$ cycles ( $p$ respectively: $p=0.032$; $0.009 ; 0.007 ; 0.01 ; 0.009)$. The proportion of patients who became independent of red blood cell and platelet transfusion increased by cycles over time, with same as $40 \%$ at sixth cycle. Median follow-up was 7 months with median OS; PFS; AMLFS: $12.3 ; 7.9 ; 11.6$ months, respectively (95\% CI). OS and AMLFS lasted longer in patients who achieved PR/CR ( $p$ respectively: $0.004 ; 0.016)$. Common grade $3 ; 4$ - complications during treatment were: infection $68.7 \%$; neutropenia $68.7 \%$; thrombocytopenia $65.6 \%$; anemia $56.2 \%$. Treatment complication death $18.7 \%$ of patients (mainly due to infection/ severe neutropenia). Conclusion: Decitabine is effective in improving hematopoiesis, reduction of blood transfusion needs and prolonging OS, PFS, AMLFS in MDS patients, especially those who get response.

Key words: Myelodysplastic syndromes, decitabine.

\section{I. ĐĂT VẤN ĐỀ}

Loan sinh tủy là môt nhóm tân sinh dòng tế bào tạo máu không đồng nhất bởi sự biệt hoá bất thường, rối loạn hình thái tế bào, giảm một hoặc nhiều dòng tế bào máu và tăng nguy cơ tiến triển thành bạch cầu cấp dòng tủy. MDS có thể gặp ở mọi lứa tuổi nhưng tỉ lệ mắc bênh tăng lên theo cấp số nhân từ sau 40 tuổi. Tần suất mắc chung trong dân số là 4,5 trên 100000 người/1 năm[5]. Đây là một bệnh lý hiếm gặp trong cộng đồng, nhưng thường gặp trong chuyên khoa huyết học

Người bệnh MDS thuộc nhóm nguy cơ trung bình, cao, rất cao có tiên lượng xấu. Nền tảng chính của điêu trị MDS là chăm sóc hố trợ và hóa trị liệu[6]. Đặc biệt ở những người bệnh MDS thuộc nhóm nguy cơ cao cần đến nhóm thuốc giảm methyl hóa (Azacitidine và Decitabine) và dị ghép tế bào gốc ở những người bệnh trẻ. Các thử nghiệm lâm sàng với các thuốc giảm methyl hóa cho thấy tỉ lệ đáp ứng đầy hứa hẹn và kéo dài thời gian OS cho người bệnh [6].

Hiện tại, với điều kiện chăm sóc nâng đỡ hóa trị liệu tốt hơn, số lượng người bênh được chẩn đoán MDS và điều trị với thuốc giảm methyl hóa nhiều hơn. Nhóm thuốc giảm methyl hóa đã được Cục quản lý thực phẩm và dược phẩm Hoa Kỳ công nhận năm 2006 [6], đưa vào các hướng dấn điều trị MDS của thế giới, cũng như phác đồ của BV.TMHH vào năm 2019. Ở Việt Nam đã có một vài nghiên cứu của các tác giả: Huỳnh Thị Bích Huyền năm 2019 về phân loại MDS theo WHO 2016, với chủ yếu thuộc loại MDS-MLD và chưa đánh giá hiệu quả điều trị MDS [2]. Năm 2019, tác giả Lại Thị Thanh Thảo đã báo cáo 9 người bệnh điêu trị decitabine, với tỉ lệ đạt $C R$ $22,2 \%$, nhưng số mẫu nghiên cứu còn hạn chế và chưa đánh giá được OS, PFS, AMLFS[1]. Năm 2020, Nguyễn Quang Hảo đã thực hiện can thiệp lâm sàng không đối chứng ở 43 người bệnh MDS điều trị decitabine với ORR 60,5\%, giảm đáng kể tỉ lệ người bệnh phụ thuộc truyền chế phẩm máu, tuy nhiên người bệnh của tác giả chủ yếu thuộc nhóm nguy cơ trung bình theo IPSS-R, người bệnh thuộc nhóm nguy cơ cao, rất cao còn hạn chế và tác giả chưa đánh giá PFS và AMLFS [3]. Nên để đánh giá chính xác hơn đặc điểm lâm sàng, sinh học và hiệu quả của decitabine trong điều trị MDS, đặc biệt trên đối tượng nguy cơ cao, rất cao. Chúng tôi thực hiện đề tài: "Bước đầu đánh giá hiệu quả điều trị của decitabine trên người bệnh loạn sinh tủy tại Bệnh viện Truyền máu Huyết học".

\section{II. ĐỐI TƯỢNG VÀ PHƯƠNG PHÁP NGHIÊN CỨU}

Thiết kế nghiên cứu: Mô tả hàng loạt ca.

Dân số nghiên cứu: Tất cả người bệnh MDS nhập viện tại BV. TMHH được điều trị decitabine trong khoảng thời gian 01/2019 đến 07/2021.

Tiêu chuẩn chọn mẫu: Thỏa tất cả tiêu chuẩn sau:

- Đủ 18 tuổi trở lên.

- Được chẩn đoán MDS dựa vào: CTM, tủy đồ và/hoặc sinh thiết tủy \pm NST đồ.

- Có điều trị thuốc decitabine. Có thể hóa trị phác đồ khác hoặc ghép tế bào gốc sau đó.

Tiêu chuẩn loại trừ: không bao gồm ít nhất một trong các tiêu chuẩn sau:

- Bệnh lý huyết học ác tính khác ngoài MDS cùng hiện diện.

- Bệnh lý tự miễn (ITP, thiếu máu tán huyết, hội chứng EVAN, Lupus), Thalassemia.

- Thiếu sắt/Thiếu acid folic/Thiếu vitamin B12.

- Những rối loạn di truyền (thiếu máu 
Fanconi, thiếu máu Diamond-Blackfan, hội chứng Shwachman-Diamond ...)

- Tứ ý ngưng decitabine sau 1 chu kỳ điều tri.

- Hồ sơ bệnh án không có đầy đủ các thông tin, xét nghiệm: CTM, tuỷ đồ và/hoặc sinh thiết tủy xương.

Phương pháp điều trị: Người bệnh được điều trị phác đồ decitabine $20 \mathrm{mg} / \mathrm{m}^{2} /$ ngày $\times 5$ ngày, từ 1 chu kỳ trở lên - tối đa đến khi bệnh tiến triển, mỗi chu kỳ cách nhau 4 tuần (có thể trì hoãn đến 8 tuần) đánh giá sau 2;4 và 6 chu kỳ: dựa trên CTM, tủy đồ \pm sinh thiết tủy.

Phương pháp tiến hành nghiên cứu: Hồi cứu hồ sơ những người bệnh thỏa tiêu chuẩn chẩn đoán MDS được điều trị decitabine từ 01/2019-07/2021. Chọn lựa người bênh thỏa các tiêu chuẩn chọn mấu và không có tiểu chuẩn loại trừ, ghi nhận thông tin hành chính, lâm sàng, đặc điểm sinh học, các xét nghiệm chẩn đoán, phân nhóm nguy cơ, ghi nhận thông tin quá trình điều trị. Phân tích số liệu đánh giá đặc điểm lâm sàng, cận lâm sàng sau điều trị.

Nhập liệu bằng phần mềm Epidata. Sử dụng phần mềm vi tính Stata 14.0 để xử lý và phân tích số liệu.

Tiêu chuẩn đánh giá đáp ứng là IWG 2006: $\mathrm{CR}$; $\mathrm{PR}$; bệnh ổn định; bệnh tiến triển; $\mathrm{HI}$; $\mathrm{mCR}$; không phụ thuộc truyền hồng cầu; không phụ thuộc truyền tiểu cầu[4].

Định nghĩa OS, PFS mà AMLFS (thời gian tính bằng tháng): OS: Từ lúc bắt đầu điều trị cho đến khi tử vong do bất kì nguyên nhân nào hoặc kết thúc nghiên cứu hoặc mất dấu. PFS: Từ lúc bắt đầu điều trị cho đến khi bệnh tiến triển hoặc tử vong do bất kì nguyên nhẩn nào hoặc kết thúc nghiên cứu hoặc mất dấu. AMLFS: Từ lúc bắt đầu điều trị cho đến khi bệnh chuyển AML (Blast $\geq 20 \%$ trong tủy hoăc phết máu ngoài biên) hoặc tử vong do bất kì nguyên nhân nào hoặc kết thúc nghiên cứu hoặc mất dấu.

\section{KẾT QUẢ NGHIÊN CỨU}

1. Đăcc điểm mẫu nghiên cứu. Từ tháng 1/2019 đển tháng 7/2021, chúng tôi đã thu thập được 32 người bệnh thỏa tiêu chuẩn chọn mẫu.

Bảng 1. Đặc điểm của người bệnh trước điều trị.

\begin{tabular}{|c|c|}
\hline Đặc điếm & $\mathbf{N = 3 2}$ \\
\hline Tuối trung vị (khoảng giới hạn) & $59(26-81)$ \\
\hline Giới tính: Nam/Nữ & $1.29 / 1$ \\
\hline Phân loại theo WHO 2016 & $\mathbf{N = 3 2 ( \% )}$ \\
\hline MDS-EB1 & $7(21,9)$ \\
\hline MDS-EB2 & $18(56,2)$ \\
\hline MDS-MLD & $6(18,8)$ \\
\hline
\end{tabular}

\begin{tabular}{|c|c|}
\hline MDS-RS-MLD & $1(3,1)$ \\
\hline $\begin{array}{c}\text { MDS-RS-SLD; MDS-SLD; } \\
\text { MDS với del(5q) đơn độc; MDS-U }\end{array}$ & 0 \\
\hline $\begin{array}{c}\text { Phân nhóm tiên lượng theo } \\
\text { IPSS-R }\end{array}$ & $\mathbf{N = 3 2 ( \% )}$ \\
\hline Rất cao & $18(56,2)$ \\
\hline Cao & $10(31,3)$ \\
\hline Trung bình & $4(12,5)$ \\
\hline Thấp, rất thấp & 0 \\
\hline Số chu kỳ điêu trị & $\mathbf{N = 3 2 ( \% )}$ \\
1 & $2(6,2)$ \\
\hline 2 & $8(25)$ \\
\hline 3 & $8(25)$ \\
4 & $3(9,4)$ \\
\hline 5 & $3(9,4)$ \\
\hline$\geq 6$ & $8(25)$ \\
\hline
\end{tabular}

Phân nhóm MDS-EB2 $56,2 \%$ và nhóm nguy cơ rất cao theo IPSS-R $56,2 \%$ chiếm tỉ lệ cao nhất. Người bệnh điều trị 1-11 chu kỳ. Ngưng sau 2-3 chu kỳ điều trị $50 \%$ chủ yếu: tử vong do biến chứng nhiễm trùng trên nền giảm bạch cầu hạt nặng $12,5 \%$, bệnh tiến triển $12,5 \%$, do không đủ kinh tế $12,5 \%$. Có 2 người bệnh điều trị 1 chu kỳ bị tử vong do biến chứng nhiễm trùng trên nền giảm bạch cầu hạt nặng.

\section{Kết quả điêuu trị}

- Phụ thuộc truyền $\mathrm{HCL}$ Không phụ thuộc truyền $\mathrm{HCL}$

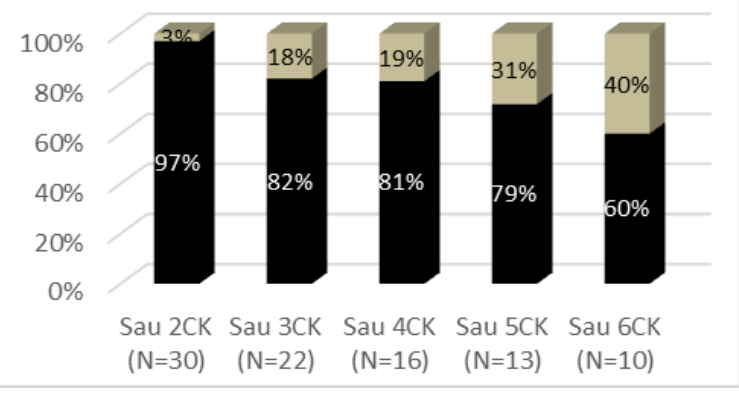

অhông phụ thuộc truyền tiểu cầu $\mathbf{\square}$ Phụ thuộc truyền tiểu cầu

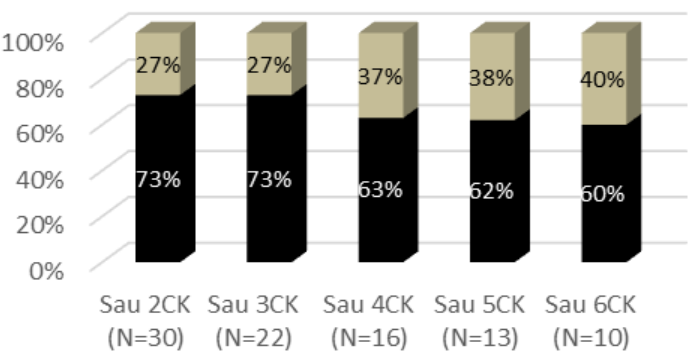

Biểu đồ 1. Nhu câu truyền hồng câu lắng

(trái), nhu cầu truyền tiểu cầu (phải)

Tỷ lệ người bệnh phụ thuộc truyền hồng cầu, tiểu cầu giảm dần lần lượt từ $97 \% ; 73 \%$ vào 2 chu kỳ đầu xuống còn $60 \%$ ở chu kỳ 6. 
Bảng 2. Kêt quả đáp ứng điều trị theo IWG 2006

\begin{tabular}{|c|c|}
\hline Đáp ứng & $\mathbf{N = 3 2 ( \% )}$ \\
\hline Đáp ứng toàn bộ (ORR)(PR+CR) & $7(21,9)$ \\
\hline Đáp ứng hoàn toàn (CR) & $4(12,5)$ \\
\hline Đáp ứng một phần (PR) & $3(9,4)$ \\
\hline Đáp ứng hoàn toàn tủy xương (mCR) & $8(25)$ \\
\hline HI (không đạt CR; PR, mCR) & $1(3,1)$ \\
\hline Bềnh ốn định (SD) & $2(6,2)$ \\
\hline Bệnh tiến triến (PD) & $8(33,3)$ \\
\hline Tứ vong do biến chứng điêuu trị & $6(18,7)$ \\
\hline
\end{tabular}

Tỉ lệ ORR (PR+CR) 21,9\% trong đó CR 12,5\%; PR 9,4\%; mCR (không đạt CR/PR) 15,6\%. Nhóm người bệnh điều trị >4 chu kỳ có tỉ lệ đạt ORR (CR+PR), CR; OS, PFS, AMLFS cao hơn nhóm điêu trị $\leq 4$ chu kỳ ( $p$ lần lượt: 0,032 ; 0,$009 ; 0,007 ; 0,01 ; 0,009$ ). Tử vong do biến chứng điêuu trị $(n=6)$ ( 5 người bệnh tử vong do biến chứng nhiềm trùng kết hợp giảm bạch cầu hạt nặng, 1 người bệnh do xuất huyết não)
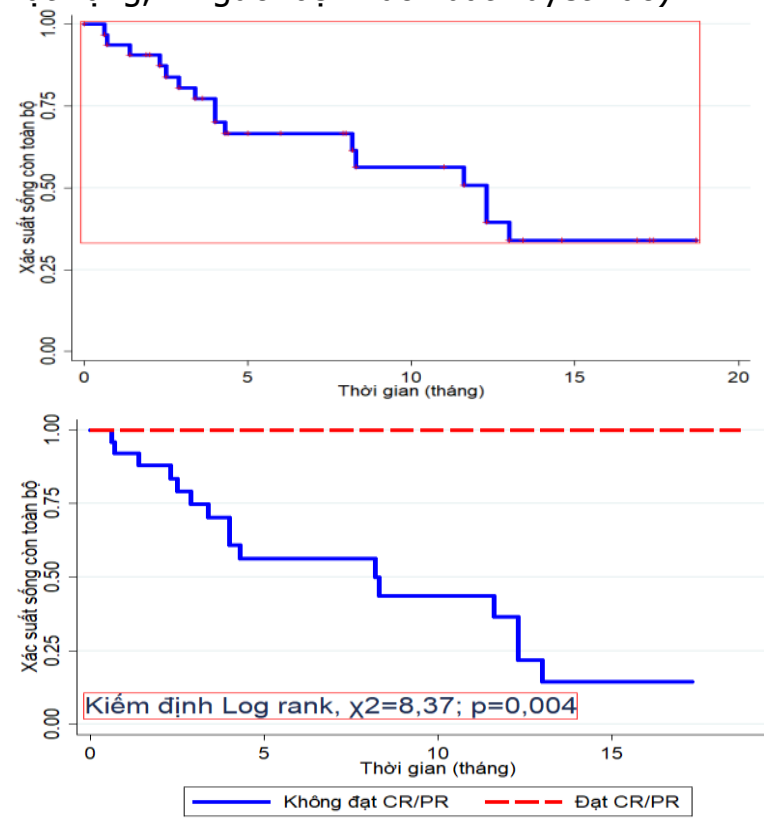

Biểu đồ 3. Biểu đồ Kaplan Meier thời gian OS (trước), OS giữa hai nhóm đáp ứng và không đáp ứng đîêu trị (sau).

3. Tác dụng phụ và độc tính của thuốc

Bảng 3. Tác dụng phụ và độc tính của thuốc theo CTCAE

\begin{tabular}{|c|c|c|c|c|c|}
\hline Tác dụng phụ & $\begin{array}{c}\text { Đố 1-2 } \\
\mathbf{N}(\%)\end{array}$ & $\begin{array}{c}\text { Độ 3-4 } \\
\mathbf{N}(\%)\end{array}$ & Tác dụng phụ & $\begin{array}{c}\text { Đô 1-2 } \\
\mathbf{N}(\mathbf{\%})\end{array}$ & $\begin{array}{c}\text { Độ 3-4 } \\
\mathbf{N}(\%)\end{array}$ \\
\hline Giảm bạch cầu & $6(18,7)$ & $20(62,5)$ & Nhiếm trùng & $1(3,1)$ & $22(68,7)$ \\
\hline Giảm bạch cầu hạt & 0 & $22(68,7)$ & Táo bón & $2(6,2)$ & 0 \\
\hline Giảm tiếu cầu & $8(25)$ & $21(65,6)$ & Nôn ói & $1(3,1)$ & 0 \\
\hline Thiếu máu & $1(3,1)$ & $18(56,2)$ & Tiêu chảy & $1(3,1)$ & 0 \\
\hline Xuất huyết & $8(25)$ & $1(3,1)$ & Suyy thận & $1(3,1)$ & $1(3,1)$ \\
\hline Sốt giảm bạch cầu hạt & 0 & $11(34,4)$ & Tăng men gan & $13(14,6)$ & $2(6,2)$ \\
\hline
\end{tabular}
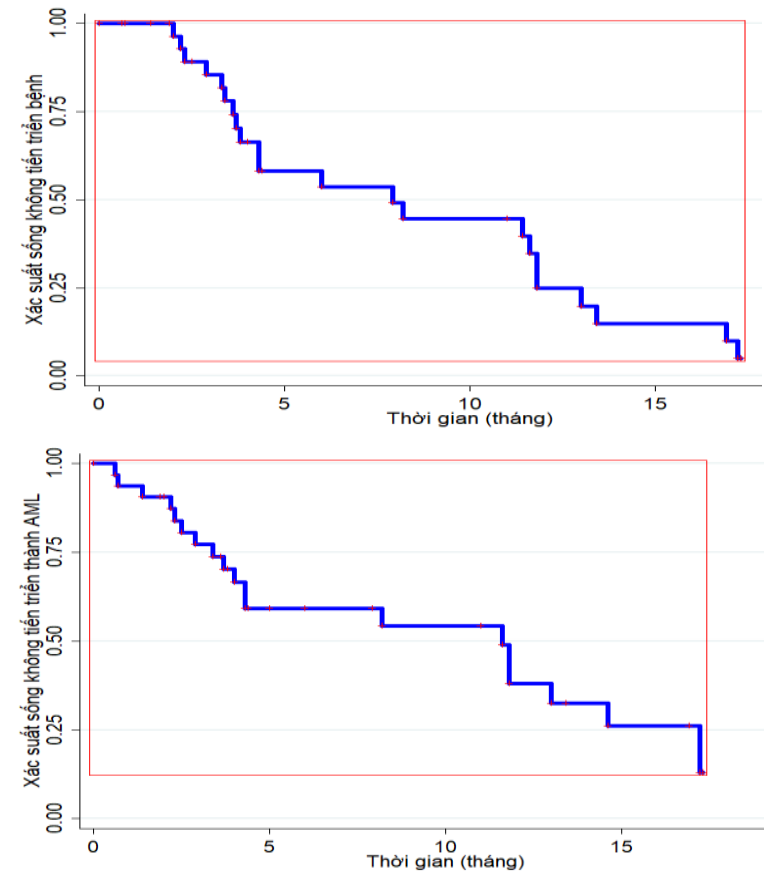

Biểu đồ 4. Biều đồ Kaplan Meier thể hiên thời gian PFS (trước), thời gian AMLFS (sau).

Thời gian theo dõi trung vị là 7 tháng, xác suất OS, PFS, AMLFS: 6 tháng lần lượt là là 66,7 $\% ; 53,6 \% ; 59,7 \% ; 12$ tháng lần lượt là 50,8\%; $24,8 \% ; 38 \%$ với OS, PFS, AMLFS trung vị lần lượt là $12,3(0,6-18,7) ; 7,9(0,6-17,3) ; 11,6(0,6-$ 17,3) (độ tin cậy 95\%).

Nhóm đạt PR/CR cho OS; PFS; AMLFS kéo dài hơn nhóm không đạt. PFS; AMLFS trung vị nhóm đạt $\mathrm{PR} / \mathrm{CR}$ lần lượt là 13,$4 ; 17,2$. OS; PFS; AMLFS trung vị nhóm không đạt CR/PR lấn lượt là : 8,3 tháng 8,$2 ; 4,3$ tháng (với lần lượt là: $\mathrm{p}=0,004 ; \mathrm{p}=0,12 ; 0,016$ )

Người bệnh thuộc nhóm nguy cơ trung bình theo IPSS-R có OS, PFS; AMLFS kéo dài hơn nhóm nguy cơ cao/rất cao. PFS; AMLFS trung vị của nhóm nguy cơ trung bình lần lượt là 13,4; 17,2 tháng và $O S, P F S ; A M L F S$ trung vị nhóm nguy $c$ ơ rất cao/cao đều bằng 8,2 tháng ( $\mathrm{p}$ lần lượt: 0,006; 0,04; 0,015). 
Tác dụng phụ và độc tính của decitabine thường gặp nhất ở trên huyết học với giảm các dòng tế bào máu và độc tính ngoài huyết học thường gặp nhất là nhiễm trùng.

\section{BÀN LUÂ̂N}

Trong nghiên cứu của chúng tôi có 32 người bệnh thỏa tiêu chuẩn chọn mẫu. MDS là bênh lý có sự liên quan rõ rệt với lão hoá và tăng dần theo cấp số nhân từ sau 40 tuổi[5]. Tuổi trung vị của nghiên cứu là 59 (26-81 tuổi), trong đó chủ yếu là từ 51-66 tuổi, tương đồng với nghiên cứu của các tác giả: Huỳnh Thị Bích Huyên năm 2019 với tuổi trung vị là 52 tuổi [2], Lại Thị Thanh Thảo năm 2015 là 51 tuổi. So với kết quả của các tác giả Germing năm 2013 tại Châu Âu là 70 tuổi và Zeidan năm 2019 tại Mỹ là 76 tuổi. Các nghiên cứu phương Tây có độ tuổi cao hơn có thể đến từ sự khác biệt về chủng tộc. Tỉ lệ nam/nữ là 1,29/1, tưy nhiên sự khác biệt không có ý nghĩa thống kê $(p=0,6)$. Phân nhóm MDS-EB và MDS-MLD là 2 phân nhóm thường gặp (Bảng 1). Phân loại nguy cơ theo IPSS-R: nhóm nguy cơ rất cao $56,2 \%$, nhóm nguy cơ cao $31,3 \%$, 2 nhóm này chủ yếu thuộc nhóm MDS-EB. Không có người bệnh thuộc nhóm nguy cơ thấp và rất thấp trong nghiên cứu, vì chỉ định sử dụng decitabine của chúng tôi thường ở nhóm nguy cơ trung bình trở lên theo hướng dẫn của NCCN[6].

Tỉ lệ người bệnh không phụ thuộc truyền chế phẩm máu tăng theo số chu kỳ được điều trị: thấp nhất ở nhóm người bệnh điêuu trị 1-2 chu kỳ (hồng cầu $3 \%$, tiểu cầu $27 \%$ ), cao nhất ở nhóm điều trị từ sau 6 chu kỳ $40 \%$. Kết quả này cho thấy decitabine giúp cải thiện huyết học, giảm nhu cầu truyền chế phẩm máu so với trước điều trị [3], [8], [9]. Về mặt đánh giá đáp ứng: số chu kỳ điều trị tị lệ thuận với đáp ứng: Nhóm người bệnh điều trị $>4$ chu kỳ có tỉ lệ đạt ORR (CR+PR), CR; OS, PFS, AMLFS cao hơn nhóm điều trị $\leq 4$ chu kỳ (với $p$ lần lượt: 0,032; 0,009; $0,007 ; 0,01 ; 0,009)$. So sánh nghiên cứu của tác giả Lại Thị Thanh Thảo năm 2015: CR (22,2\%), nhưng tỉ lệ thất bại điều trị là $66,6 \%[1]$; tác giá Nguyển Quang Hảo năm 2021: CR+PR: 60,5\%, CR: $41,9 \%$; PR; 18,6\%[3]. Nghiên cứu của chúng tôi có tỉ lệ đáp ứng tương đồng so với nghiên cứu ADOPT năm 2009 [9] và cao hơn so với tác giả Kantarjian năm 2006 (CR: 9\%, PR: 8\%) [7]. Đặc điểm nguy cơ mẫu nghiên cứu khác nhau cho từng cơ sở y tế, đồng thời số mẫu của chúng tôi cùng với các nghiên cứu trong nước chưa đủ lớn nên có sư chênh lệch về tỉ lệ đáp ứng. Kết quả nghiên cứu bước đầu cho thấy decitabine là một phương án lựa chọn cho người bệnh, giúp cải thiện tình trạng huyết học và giảm nhu câuu truyền chế phẩm máu. Nhóm người bênh đáp ứng điều trị đồng thời cũng kéo dài thời gian $O S$ và AMLFS có ý nghĩa $(p=0,004$; 0,016) (sơ đồ 3).

Mục tiêu chính trong điều trị cho người bệnh MDS là cải thiện chất lượng cuộc sống, kéo dài thời gian OS và AMLFS. Thời gian theo dõi trung vị 7 tháng với xác suất OS 6 tháng là $66,7 \%, 12$ tháng là $50,3 \%$. OS trung vị là $12,3(0,6-18,7)$ tháng (độ tin cậy 95\%) (biểu đồ 3). Kết quả này thấp hơn của tác giả Nguyễn Quang Hảo với OS trung vị là 25,6 tháng và OS 18 tháng $62,6 \%$ và thấp hơn với nghiên cứu ADOPT với OS trung vị là 19,2 tháng, OS 1 năm $66 \%$. Có thể giải thích được sự khác biệt này là người bênh của 2 nghiên cứu ADOPT và của tác giả Nguyễn Quang Hảo chủ yếu thuộc nhóm nguy cơ trung bình theo IPSS-R, còn người bệnh của chúng tôi chủ yếu thuộc nguy cơ cao, rất cao. Người bệnh thuộc nhóm nguy cơ trung bình theo IPSS-R có OS, PFS; AMLFS kéo dài hơn nhóm nguy cơ cao/rất cao. PFS; AMLFS trung vị của nhóm nguy cơ trung bình lần lượt là 13,4; 17,2 tháng và OS, PFS; AMLFS trung vị nhóm nguy cơ rất cao/cao đều bằng 8,2 tháng ( $\mathrm{p}$ lần lượt: 0,$006 ; 0,04$; $0,015)$. Một phần là do thời gian theo dõi của chúng tôi chưa đủ dài. Xác suất PFS, AMLFS: 6 tháng lần lượt là: $53,6 \% ; 59,7 \%$; 12 tháng lần lượt là: $24,8 \% ; 38 \%$, trung vị lần lượt là: 7,9 $(0,6-17,3) ; 11,6(0,6-17,3)$ (độ tin cậy 95\%) còn thấp[7] (biểu đồ 4).

Trong quá trình điều trị bằng decitabine, tác dụng phụ và độc tính của thuốc có thể dự đoán được. Tuy nhiên, đa số người bệnh MDS thường là người cao tuổi và có nhiều bệnh lý nền nên tác dụng phụ của thuốc gặp khá phổ biến. Biến chứng độ III-IV thường gặp trong quá trình điều trị là: nhiễm trùng $68,7 \%$; giảm bạch cầu hạt $68,7 \%$; giảm tiểu cầu $65,6 \%$; thiếu máu $56,2 \%$; đặc biệt trong đó có 5 người bệnh tử vong do biến chứng nhiễm trùng/giảm bạch câu hạt nặng. Kết quả này khá tương đồng với tác giả Hussain năm 2004 [8].

\section{KẾT LUẬN}

Kết quả từ nghiên cứu cho thấy MDS thường găp ở người bênh lớn tuổi, với đặc trưng là giảm các dòng tế bào máu, hình ảnh loạn sinh trong tủy và có thể kèm bất thường NST. Sử dụng decitabine trong điều trị MDS cho thấy hiệu quả trong giảm nhu cầu truyền chế phẩm máu, giúp cải thiện huyết học, đồng thời giúp kéo dài thời gian OS, PFS, AMLFS cho người bệnh, đặc biệt ở 
nhóm người bênh có đáp ứng. Với độc tính và tác dụng phụ của thuốc khá thường gặp.

\section{TÀI LIẸU THAM KHẢO}

1. Lai Thị Thanh Thảo, Huỳnh Hồng Hoa. (2015), "Báo cáo các trường hợp rối loạn sinh tủy được điêuu trị bằng Decitabine tại bệnh viện Chợ Rấy", Y hoc thành phố Hồ Chí Minh, (1), pp. tr.1.

2. Huỳnh Thi Bích Huyên, Lê Phương Thảo, Nguyễn Hữu Nhân, et al, Chẩn đoán, phân loai và tiên lượng loạn sinh tùy theo WHO 2016 tai bệnh viện Truyền máu Huyết học thành phố Hồ Chí Minh, 2019: Sở y tế, bệnh viện Truyên máu Huyết học. pp. tr34.

3. Nguyễn Quang Hảo, Trân Tuấn Anh, Lưu Thi Thu Hương. (2021), "Kết quả điều trị loạn sinh tủy bằng decitabine tại viện Huyết hoc - Truyền máu Trung ương", Tap chí nghiên cứu y hoc, pp. tr.1-9.

4. Cheson Bruce $D$, Greenberg Peter $L$, Bennett John $\mathbf{M}$, et al. (2006), "Clinical application and proposal for modification of the International Working Group (IWG) response criteria in myelodysplasia", Blood, 108 (2), pp. pp.419-425.
5. Kenneth Kaushansky Marshall A. Lichtman, et al,. (2016), "Myelodysplastic syndromes", Williams Hematology, 9th, Mc Graw Hill, New York Chicago San Francisco Athens London Madrid Mexico City Milan New Delhi Singapore Sydney Toronto, pp. pp.1341.

6. NCCN. (version 3.2021), "Myelodysplastic Syndromes".

7. Kantarjian Hagop, Issa Jean-Pierre J, Rosenfeld Craig S, et al. (2006), "Decitabine improves patient outcomes in myelodysplastic syndromes: results of a phase III randomized study", Cancer: Interdisciplinary International Journal of the American Cancer Society, 106 (8), pp. 1794-1803.

8. Saba Hussain, Rosenfeld Craig, Issa JeanPierre, et al, First report of the phase III North American trial of decitabine in advanced myelodysplastic syndrome (MDS), 2004, American Society of Hematology.

9. Steensma David P. (2018), "Myelodysplastic syndromes current treatment algorithm 2018", Blood cancer journal, 8 (5), pp. 1-7.

\section{ĐĂC ĐIỂM DİCH TỄ, LÂM SÀNG CỦA BÊNNH THIẾU VITAMIN D Ở TRẺ EM DƯớI 5 TUỔI TẠI TRƯờNG THỌ, AN LÃO, HẢI PHÒNG, NĂM 2017}

\section{TÓM TẮT}

Muc tiêu: Xác đinh tỷ lê thiếu vitamin D ở trẻ dưới 5 tuổi tại Trường Thọ, An Lã்o năm 2017 và mô tả 1 số triêu chứng lâm sàng của bênh còi xương ở đối tượng nghiên cứu. Đối tượng: là trẻ em $\leq 60$ tháng sinh ra và có hô khẩu thường trú tai xã Trường Tho huyên An Lão. Phương pháp: Nghiển cứu mô tả cắt ngang và hồi cứu. Kết quả và kết luân: Tỷ lê trẻ trai là 54,8\% cao hơn trẻ gái là $45,2 \%$, tỷ lệ trai/gái là 1,2. Lứa tuổi từ 24- 60 tháng chiếm tỳ lệ cao nhất 75,44\%. Tỷ lệ thiếu/hụt Vitamin D ở trẻ là 93,86\%, trong đó trẻ trai là $54,21 \%$ cao hơn trẻ gái là $45,79 \%$. Tỷ lệ trẻ thiếu/hụt Vitamin D cao nhất là ở lứa tuổi từ 24- 60 tháng $(76,17 \%)$. Trong nghiên cứu của chúng tôi, khi khám sàng lọc dựa vào các triệu chứng lâm sàng đã phát hiện 123 trẻ có biểu hiện quấy khóc $(53,95 \%)$ trẻ có dấu hiệu ngủ không yên giấc, giật mình là 124 trẻ $(54,39 \%)$, trẻ có dấu hiệu vã mô hồi, rụng tóc là 124 trẻ $(54,39 \%)$.

Tư khóa: Thiếu vitamin D, hụt vitamin D, còi xương.

\section{SUMMARY \\ THE INCINDENCE, SYMTOM OF VITAMIN D}

*Bệnh viện Trẻ em Hải Phòng

**Trường Đai hoc Y Dược Hải Phòng

Chịu trách nhiệm chính: Nguyễn Thị Ngọc Yến

Email: bsyenbvte@gmail.com

Ngày nhận bài: 3.6.2021

Ngày phản biên khoa hoc: 2.8.2021

Ngày duyệt bài: 9.8.2021

\section{DEFICIENCY IN CHILDREN UNDER 5 IN} TRUONG THO, AN LAO, HAI PHONG IN 2017

Objectives: estimate the prevelence of vitamin $D$ deficiency in children under 5 at Truong Tho, An Lao, in 2017and describe some clinical signs of ricket in these participants. Population: included 228 children under 5 who were born in Truong Tho, An Lao. Method: It was a cross sectional study. Results and Conclusions: More males $(54.8 \%)$ than females $(45.2 \%)$ paticipated in the study, male/female ratio was 1.2. 24- 60 group represented the highest rate $75.44 \%$. The prevalence of Vitamin D insufficiency and deficiency were $93.86 \%$ and among them, $54.21 \%$ males and $45.79 \%$ females. The Vitamin D insufficiency and deficiency was the highest in 24- 60 months group (76.17\%). There were 123 children with crying (53.95\%), not well sleeping, startle (54.39\%), sweating and hair loss (54.39\%).

Keywords. Insufficiency, Deficiency, ricket.

\section{I. ĐăT VẤN ĐỀ}

Từ thế kỷ 19 vitamin $D$ được biết đến như là một hoạt chất có ảnh hưởng đến sự phát triển và duy trì xương. Các phát hiện này cũng đã chỉ ra thiếu hụt vitamin $D$ không chỉ làm tăng nguy cơ mắc bệnh loãng xương, tim mạch, cao huyết áp, đái tháo đường, vẩy nến, viêm đường ruột, viêm khớp, viêm gan, nhiễm trùng, lao phổi, v.v... mà còn tăng nguy cơ mắc bệnh ung thư'. Người thiếu vitamin $D$ thường hay bị đau nhức 